\title{
Do we need a Wider Therapeutic Paradigm for Heart Failure with Comorbidities? - A Remote Australian Perspective
}

\author{
lyngkaran $\mathrm{P}^{1,2,3,5 *}$, Thomas $\mathbf{M}^{2}$, Sanders $\mathrm{P}^{4}$, Hare $\mathrm{DL}^{6}$, Majoni $\mathbf{W}^{1}$, Brady $\mathbf{S}^{7}$, Nadarajan $\mathrm{K}^{1,3}$, Ilton $\mathbf{M}^{1,3}$ and $\mathbf{B r o w n}$ \\ ${ }^{1}$ Royal Darwin Hospital, P.O. Box 41326, Australia \\ ${ }^{2}$ Baker IDI Heart Research Institute, PO Box 6492 St Kilda Road Central Melbourne Victoria 3004, Australia \\ ${ }^{3}$ Darwin Private Hospital, Rocklands Drive, Tiwi, NT 0811, Australia \\ ${ }^{4}$ Centre of Heart Rhythm Disorders, University of Adelaide, Royal Adelaide Hospital, Australia \\ ${ }^{5}$ Flinders University, Australia \\ ${ }^{6}$ Research Cardiology Department, Austin Health and University of Melbourne, Australia \\ ${ }^{7}$ Alice Springs Hospital, PO Box 2234, ALICE SPRINGS NT 0871, Australia \\ IIndigenous Health, SAHMRI, Adelaide, Australia
}

\begin{abstract}
Congestive Heart Failure a leading cause of morbidity and mortality is often associated with comorbidities and with it polypharmacy. Improved pathophysiological understanding, the available therapeutics, clinical guidelines and structured programs for comprehensive care have not benefited all clients in the Northern Territory of Australia. The Northern Territory has both a unique geography and demography including a sizeable Indigenous population. Additional factors that can affect heart failure management are prevalent in remote areas and are not well addressed within randomized controlled trials. This review is focused on building a case for widening the therapeutic paradigm for heart failure with comorbidities. We focus on a brief overview of heart failure and its associated comorbidities, the common overlapping physiological processes, the interpretation of the external validity of trial evidence, and finally exploring the available evidence for the important therapies within the guidelines. A need to consider a wider therapeutic paradigm may also have relevance for clients in other health systems.
\end{abstract}

Keywords: Heart failure; Indigenous; Northern territory; Remote; Comorbidity

Abbreviations: ACE-I: Angiotensin Converting Enzyme Inhibitor; AGE: Advanced Glycosylation End Products; ARB: Angiotensin Receptor Blockade; $\beta \beta$ : Beta Blockers; CCB: Calcium Channel Blocker; CHF: Congestive Heart Failure; COPD: Chronic Obstructive Pulmonary Disease; CRF/I: Chronic Renal Failure/Insufficiency; DM: Diabetes Mellitus; HT: Hypertension; IR: Insulin Resistance; MACE: Major Cardiovascular Adverse Effects; NO: Nitric Oxide; NT: Northern Territory; OSA: Obstructive Sleep Apnea; RAAS: ReninAngiotensin-Aldosterone-System; RCT: Randomised Control Trials; RF: Risk Factors; RNS: Reactive Nitrogen Species; ROS: Reactive Oxygen Species; SNS: Sympathetic Nervous System

\section{Introduction}

The Northern Territory (NT) of Australia comprises a large area servicing close to a quarter of a million clients. It has a land mass six times that of Great Britain. Two major teaching public hospitals provide the majority of heart failure tertiary care. In this region, congestive Heart Failure (CHF) is a chronic disease that causes significant morbidity and mortality. It is usually associated with comorbidities and with this polypharmacy. The population demographics are diverse with a sizeable Indigenous population approaching $30 \%$. Unfortunately Indigenous clients suffer disproportionately in disease burden and comorbidities, as do all clients living remotely from service inequalities. It appears that the available CHF therapies and its delivery through the recommended guidelines have not provided similar benefits compared to urban Australians and other groups in large CHF databases. There is a developing clinical perspective, which is unfortunately subjective from a lack of prospective data, that this 'one-shoe fit all' approach could be an important negative factor for this subset of the NT population. The Northern Territory Heart Failure Initiative-Clinical Audit (NTHFI-CA), a prospective database on CHF admissions, will help answer some of these questions. The process of setting up this database has highlighted several important factors including demographics, geography, and service and workforce issues. These issues compound the inability to meet the rigid clinical trial level support. As these take a reasonable time to resolve we explore simpler measures in the therapeutic paradigm, which could make a small but perhaps important difference. The opportunities for improved diagnostics and comprehensive care have been addressed elsewhere [1-3]. This review focuses on building an early foundation for a more liberal therapeutic approach for CHF with comorbidities. We provide a contextual overview of the associated comorbidities, the areas of common overlap in pathophysiology, a review of the external validity of randomized controlled trials and discussions on how all these factors could shape broader prescribing practices. In this we focus particularly on agents with longer activity and broader physiological benefits thus addressing pill burden, compliance and effects on comorbidities.

\section{Common Comorbidities Associated with Congestive Heart Failure}

Forty percent of CHF clients can suffer with up to five or more comorbidity, a rate that is likely higher in the NT. Large CHF trials

${ }^{*}$ Corresponding author: Pupalan lyngkaran, MBBS FRACP, Cardiologist Royal Darwin Hospital, Senior Lecturer Flinders University, Research Fellow Baker IDI/ FHBHRU, Darwin Private Hospital, Rocklands Drive, Tiwi, NT 0811, Australia, Tel: +618 8404 2323; E-mail: balaniyngkaran@hotmail.com

Received August 24, 2013; Accepted October 18, 2013; Published October 20 2013

Citation: lyngkaran P, Thomas M, Sanders P, Hare DL, Majoni W, et al. (2013) Do we need a Wider Therapeutic Paradigm for Heart Failure with Comorbidities? - A Remote Australian Perspective. Health Care Current Reviews 1: 106. doi: 10.4172/2375-4275.1000106

Copyright: (c) 2013 lyngkaran P, et al. This is an open-access article distributed under the terms of the Creative Commons Attribution License, which permits unrestricted use, distribution, and reproduction in any medium, provided the original author and source are credited. 
have either excluded these patients (outright or by illness grades) or underreported important demographic and clinical details. Other trials that were armed with a broader inclusion also failed to reflect this wider cohort when the actual enrollment remained narrow or when sicker patients were excluded in the run in period [4-6]. As these trials have formed the backbone of our evidence, this has also reflected in the guidelines. Guideline updates have factored comorbid illnesses however the depth of discussion particularly on physiology and external validity for such clients as ours remains insufficient. The general themes from available evidence highlight seven important direct contributors [6-10]:

- Hypertension (HT), the most important comorbidity and contributor to all forms of CHF is present in more than $55 \%$ of cases. At least half these patients are also insulin resistant (IR). Untreated at least $50 \%$ can develop HF [6-8];

- Ischemic Heart Disease (IHD) the most important cause for CHF mortality is present in $30 \%$ of cases. This is likely underreported as sicker patients and those with active ischemia were common exclusions from many RCT [7];

- Diabetes Mellitus (DM) and asymptomatic hyperglycemia ( $\approx 40 \%)$, is overrepresented, likely under recognized and has worse morbidity and mortality where every $1 \%$ increase in $\mathrm{HbAlc}$ is associated with an $8 \%$ increase in mortality. In addition insulin resistance (IR) rates could be $2-3 \mathrm{x}$ higher and $>70 \%$ of DM also have HT. CHF is also a common exclusion from DM trials $[6,9,11,12]$;

- Obesity-Metabolic (MetS) and Sleep-Respiratory Axis - including constellation of central obesity, blood pressure abnormalities, glucolipotoxicity and sleep apnea are common. Sleep apnea and respiratory conditions often co-exist in $30-40 \%$ and can be a diagnostic confounder. Improving IR improves HT and CHF [8,12-15];

- Hyperlipidemia is common in CHF trials and greater among DM, $\mathrm{HT}$ and MetS is seen in more than $30 \%$ of cases;

- Renal failure the strongest predictor of mortality even greater than LVEF is common and has a bidirectional effect, with increasing morbidity and mortality with grade [16];

- Rheumatic Heart Disease is a common cause of CHF among Indigenous clients [3].

Important secondary associations and contributors include: Atrial arrhythmias, reported in over $40 \%$ of CHF trials, are an important cause of symptoms and a marker of severity and prognosis (14\% of early deaths within 4 months of CHF diagnosis). They occur with increasing NYHA grade, age, non-ischemic and diastolic etiology $[6,17]$; Neuropsychological factors, such as stroke, mood and behavior (10-20\%), cognitive function (35-50\%), depression (13-77\%) and sexual dysfunction $[6-8,18,19]$ are often given less importance; Finally other non-cardiac factors, chronic anemia, arthritis/ osteoporosis (20\%) substance abuse (alcohol, smoking), and specific to NT environmental factors e.g. weather and race. Lastly factors such as large alcohol consumption and long-term unregulated use of NSAID and Cox 2 although not directly associated with CHF can promote cardiomyopathy with other stressors [20]. These numerous comorbidities are important as they can affect the pill burden and alter the efficacy of certain CHF therapies.

\section{Common Pathophysiology of Heart Failure and Comorbidities}

When we look at the common directly contributing comorbidities and the pathophysiological processes in the cardiovascular-metabolicrenal axis we can identify common overlaps. Firstly, regardless of the primary organ involved, all these processes activate counter regulatory systems predominately the Renin-Angiotensin-Aldosterone-System (RAAS), Endothelin, Sympathetic Nervous System (SNS), inflammatory and/or coagulation systems. These systems are activated to different degrees initially and are also activated secondarily. Secondly, when these processes are activated the diverse intracellular and extracellular signaling (e.g. proinflammatory cytokines, growth factors, receptor regulation) leads to 3 common and important imbalances. These include imbalances of nitric oxide (NO), toxic chemicals e.g. oxidative species and advanced glycation end products (AGE). These imbalances will eventually feedback on the organ and spill over onto secondary organs. As these processes proceed unregulated, the primary etiology may soon be indistinguishable from secondary end organ damage (Figure 1).

These processes are important as they occur at the forefront of every cell in the organs and affect the health of the circulatory system. More specifically: reactive oxygen and nitrogen species are short-lived chemicals involved in cell signaling that are scavenged by antioxidant enzymes when in access. Prolonged stress leads to a loss of redox homeostasis and an excess of free radicals and byproducts (oxidized particles). This contributes to chronic illness, proinflammatory/ profibrotic pathophysiology or Oxidative Stress; Nitric oxide, produced in the vascular endothelium, is vital for maintaining the tone and health in the vasculature of every organ. With endothelial dysfunction, NO deficiency leads to vasoconstriction and impaired oxygen delivery; AGE result from the non-ezymatic glycation and oxidation of proteins, lipids and nucleic acids in hyperglycemia. Increasing blood levels directly contributes to and progresses CHF. AGE can secondarily lead to $\mathrm{CHF}$ by a vast array of negative effects on healthy organs [21-32]. In summary there are common overlaps in activating regulatory systems and consequences of homeostatic imbalances. Pharmacotherapies have varying benefits for prevention, stabilization and regression. Modulation with aspirin, RAAS antagonist and statins are of greatest importance due to diversity of effects. Agents with prolonged reliable activity, high specificity, and extra class effects such that they provide a stable primary effect while being neutral or enhancing other effectors, are beneficial.

\section{Interpreting Trial Evidence for Clients who do not meet Enrolment Criteria}

The Randomized Controlled Trial is the gold standard for establishing evidence for an observed pathology and the therapy, which aims to alter it. In doing so we can conclude if a treatment effect on that disease process is most likely related to the prescribed therapy. The strength of RCT's relates to a strong design and high internal validity (which can de deduced from first principles) and its control of confounders by the clinical criteria it uses to enroll participants. Unfortunately it is also the enrollment criterion that is the 'Achilles heel' of such studies. The failure to enroll a wider cohort limits the external validity of such studies and its universal generalizability. In addition many studies often present the methodology vaguely, as such it is difficult to replicate, or do not clarify questions of drug usage i.e. under, over or misuse. The study conclusions however would often suggest otherwise. Health and industry regulators also attach little 
Citation: lyngkaran P, Thomas M, Sanders P, Hare DL, Majoni W, et al. (2013) Do we need a Wider Therapeutic Paradigm for Heart Failure with Comorbidities? - A Remote Australian Perspective. Health Care Current Reviews 1: 106. doi: 10.4172/2375-4273.1000106

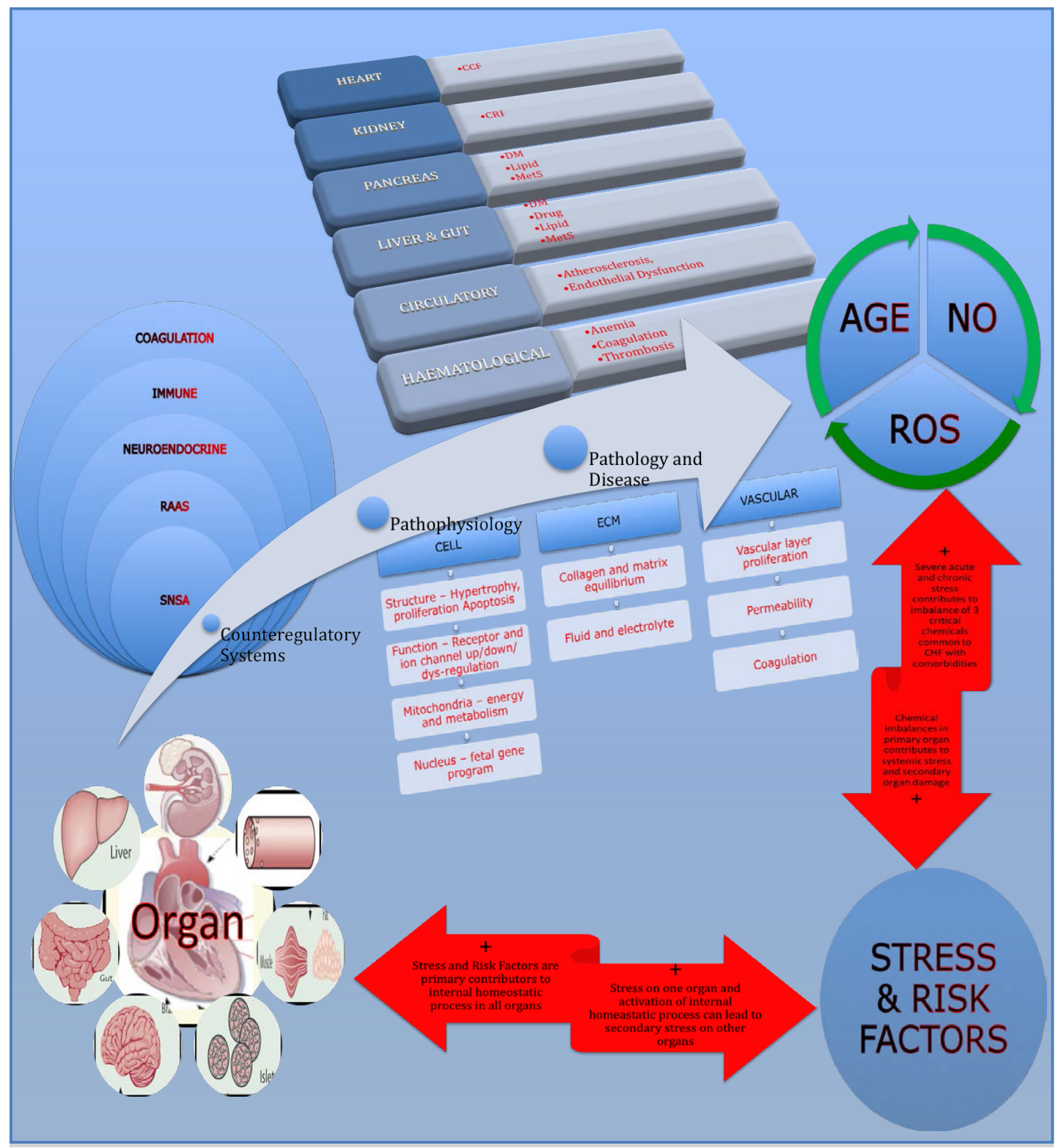

Stress and risk factors can directly affect the heart or other organs. When the primary condition is CHF with comorbidities there is initial activation of counterregulatory systems. Interconnected signaling can recruit other systems or feedback on this system. If the stress is sustained this leads to pathophysiological changes within the organ. Pathology and disease results when these changes take over the normal function of that organ or is cause for further stress. The homeostatic imbalance in signaling and metabolic processes at the chemical level is expressed through AGE, NO and ROS. This eventually has a systemic effect that contributes to development or progression of secondary conditions e.g. CHF through SNSA and reduced peripheral blood flow can contribute to IR, HT and CRI. Targeting specific diseases may not halt these long-term processes. (Modified from Ref 31)

Figure 1: A simplistic view of Cardiovascular-Metabolic-Renal Axis Pathways.

importance to this [33-36]. "The practice of medicine ought to be based on solid scientific evidence, not on assumptions or extrapolations [37]", and this is particularly so for those who sit on the margins of the study enrolment criteria. In ideal circumstances RCT should be designed and reported to facilitate broader approval, however, many studies are driven or financed through industry support, which can control the publication and content of results [38-42]. It is widely and rightfully accepted that study results do in fact appeal to the broader community. Thus the points raised perhaps carriers its greatest weight for populations such as those in the NT, with the previously highlighted issues. Physicians who care for these clients have the responsibility to ensure those at the fringes receive equal consideration.

Bearing this in mind there are important points we need to consider: Firstly, the manner in which these findings are interpreted. The RE-AIM framework is a good tool to assess public health impacts of translational research and so indirectly the external validity of the study. In this there is often a gap in the resources used to acquire that data, the clinical support and the realistic real world translation. There are few recommendations when this aspect is deficient; Secondly, do RCT answer the question primarily of physiological effects or 
Citation: lyngkaran P, Thomas M, Sanders P, Hare DL, Majoni W, et al. (2013) Do we need a Wider Therapeutic Paradigm for Heart Failure with Comorbidities? - A Remote Australian Perspective. Health Care Current Reviews 1: 106. doi: 10.4172/2375-4273.1000106

otherwise? For e.g. drug design starts when evidence supports a pathophysiological process as causation of disease. A ligand that blocks receptors altering that process is developed into a clinical drug. Various phases of clinical trials (I-III) bring these agents into clinical use. Phase IV or post marketing studies are often delayed or non-existent. Looking specifically at drug classes there are probably marginal differences between agents within the class. However, extra class effects are unique. Unfortunately replicating RCT's with similar baseline efficacy are infrequent. As such clinical guidelines do not support these agents as first line. Of relevance to the NT is how we decide on these marketed benefits for CHF clients with comorbidities (Figure 2); finally, conducting clinical trials are costly. The pharmaceutical manufacturer often absorbs this burden. Through a clinical trial agreement, perhaps relinquishing the freedom of trial design, studies are conducted in a real but controlled clinical setting. Unfortunately we are a long way from identifying alternative approaches for this aspect. Despite this perhaps there are simpler approaches we could explore. If we looked to plan prescribing practices, especially for clients with numerous medications, firstly we should consider the ease of use and translating this into long-term compliance. Secondly we could look at the comorbidities, address common physiological processes and finally identify the agents. If for example a client that would normally qualify for a particular drug class, perhaps an argument could be put forth where the novel agent could similarly be made available as first line, via the relevant regulatory channels such as the Pharmaceutical Benefit Scheme. This may appear a sensible option however several issues need consideration. Firstly justification for this increased flexibility to the funding bodies and secondly clinical trial standard accountability with these prescribing practices.

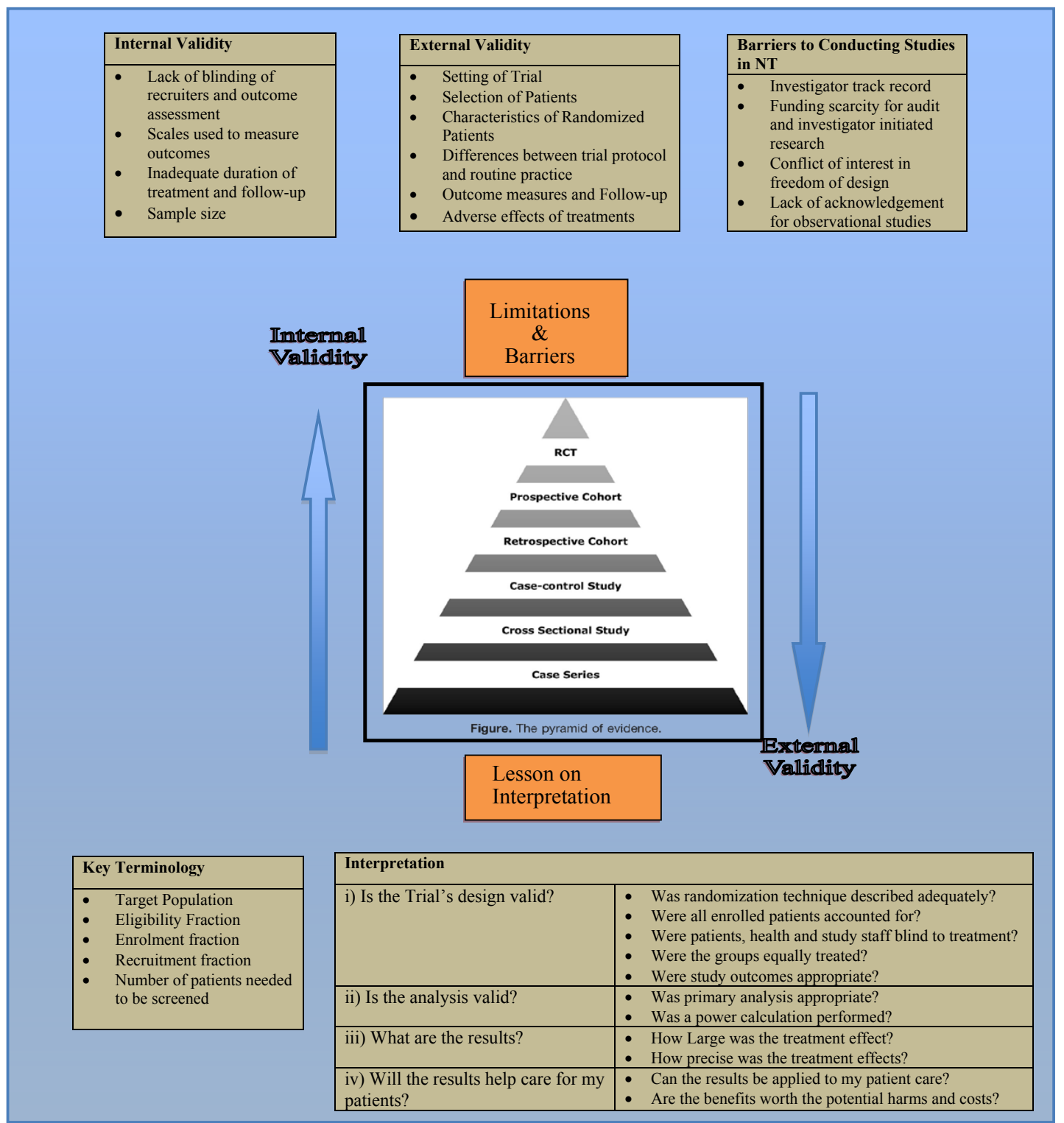

Internal and external validity determine the strength and applicability of RCT. External validity is important in deciding relevance of result for a clinician's client. The more rigid the exclusion criteria the lesser is the external validity. Key terminology and the 4 listed points on interpretation also help determine the translation of results (Image and concepts adapted from ref 35,36).

Figure 2: Study Design, Interpretations and Implications for Remote CHF Clients. 
Citation: Iyngkaran P, Thomas M, Sanders P, Hare DL, Majoni W, et al. (2013) Do we need a Wider Therapeutic Paradigm for Heart Failure with Comorbidities? - A Remote Australian Perspective. Health Care Current Reviews 1: 106. doi: 10.4172/2375-4273.1000106

Page 5 of 9

\section{What is the Level of Evidence for HF Therapies in the NT Context?}

Summing the points thus far comorbidities are common in CHF and clinical trials cannot be generalized to all clients. Let's look at one such example from the NT, bearing in mind that compliance is an important factor in clinical outcomes [43]. A 50 year Indigenous male with CHF, stage 3 renal impairment and several other metabolic comorbidities. He lives in a remote community, considers his values traditional, weighs $>110 \mathrm{~kg}$, has a chronic cough from ongoing tobacco use, erectile dysfunction (reluctantly disclosed to male doctor years later), undiagnosed sleep apnea, and may come home late or travel for cultural business, where he fails to take the evening dose or carry his dosette. He is prescribed Aspirin $100 \mathrm{mg}$, Frusemide $40 \mathrm{mg}$ bd, Lipitor $80 \mathrm{mg}$, Metformin $2 \mathrm{gm}$ tds, Metoprolol XR $47.5 \mathrm{mg}$, Ramipril $5 \mathrm{mg}$; was previously on Amlodipine and Thiazide diuretic. He takes $>10$ pills spread over 3 meals. The pills are in a dosette and stored at home. Compliance is unclear, speculated as poor. With this scenario we explore medication regime and rationale closer (Table 1).

Beta-blockers $(\beta \beta)$, reverse SNSA effects on the heart, likely share similar effects across class [44] when targeting lower heart rates between $60-70 \mathrm{bpm}$ [45]. These broad assumptions are based on combinations of meta-analysis and RCT, and debate continues

\begin{tabular}{|c|c|c|c|c|c|c|c|c|c|c|c|}
\hline & CHF & DHF & IHD & DM & Chol & CRF & Mood & Race & Additional properties & Dose Combination & Notes \\
\hline \multicolumn{12}{|l|}{ ACE-inhibitor } \\
\hline CaptoprilY & + & $\sim$ & + & + & + & + & - & + & - & 6.25-50tds NA & \multirow{6}{*}{$\begin{array}{l}\text { Some concern of ACE-I effect as a class } \\
\text { on blacks due to baseline renin levels. } \\
\text { Newer agents more costly. }\end{array}$} \\
\hline Enalapril ${ }^{* *}$ & ++ & $\sim$ & ++ & + & + & + & - & + & - & 2.5-20bd C & \\
\hline Lisinopril $^{*}$ & + & $\sim$ & + & + & + & + & - & $\sim$ & - & 2.5-35od NA & \\
\hline Ramipril** & ++ & $\sim$ & ++ & + & + & + & - & + & - & $2.5-10 \circ d / 5 b d C$ & \\
\hline Trandolaprilr & + & $\sim$ & + & + & + & + & - & + & - & $0.5-4$ od C & \\
\hline Perindopril & $\sim /+$ & $\sim$ & + & + & + & + & - & + & - & 1.25-10od CD & \\
\hline \multicolumn{12}{|l|}{ Beta Blockers } \\
\hline Carvedilol $^{* *}$ & ++ & $\sim /+$ & + & $\sim /+$ & $\sim /+$ & + & $\sim$ & $\sim$ & $\alpha 1$ & $3.125-25-50 \mathrm{bd}$ & \multirow{4}{*}{ Vasodilatory $\beta \beta$ are preferred in the MetS. } \\
\hline Bisoprolol & + & $\sim$ & + & $\sim$ & $\sim$ & $\sim$ & $-/ \sim$ & $\sim$ & - & $1.25-10$ od & \\
\hline Metoprolol XL & + & $\sim$ & $\sim /+$ & $-/ \sim$ & $-/ \sim$ & $-1 \sim$ & $-/ \sim$ & $\sim$ & - & $12.5-200 \mathrm{od}$ & \\
\hline Nebivolo/\$ & + & $\sim /+$ & + & $\sim /+$ & $\sim /+$ & + & $\sim$ & $\sim$ & NO & $1.25-10 \mathrm{od}$ & \\
\hline \multicolumn{12}{|l|}{ ARB } \\
\hline Candersartan** & ++ & $\sim /+$ & + & + & + & + & - & + & - & 4-32od D & \multirow{5}{*}{$\begin{array}{l}\text { Candersatan has strongest evidence. } \\
\text { Telmisartan most potent } 24 \mathrm{hr} \mathrm{BP} \text { and } \\
\text { prevention. Cost higher for newer agents. }\end{array}$} \\
\hline Valsartan** & + & $\sim$ & ++ & + & + & + & - & + & - & 40-160bd D & \\
\hline Losartan*\$ & + & $\sim$ & + & + & + & + & - & $\sim$ & - & 50-150od NA & \\
\hline Irbesartan & + & $\sim$ & + & + & + & + & - & + & - & 75-300od D & \\
\hline Telmisartan & $\sim /+$ & $\sim /+$ & + & + & + & + & - & + & PPAR-y activation & 20-80od CD & \\
\hline \multicolumn{12}{|l|}{ MRA } \\
\hline Spironolactone & + & $\sim /+$ & $?$ & $-/ \sim$ & + & - & - & + & - & $25-50 \mathrm{od}$ & $\begin{array}{l}\text { Gynecomastia } 10 \% \text {; greater risk sexual } \\
\text { side effect with dose and duration of use }\end{array}$ \\
\hline Eplerenone & + & $\sim /+$ & + & $\sim$ & + & - & - & + & Receptor specificity & $25-50 o d$ & Cost; ADI more likely \\
\hline \multicolumn{12}{|c|}{ OTHER AGENTS } \\
\hline Co-plavix & ++ & N/A & ++ & + & + & + & N/A & + & Dual antiplatelet & $75 / 100$ od & Mulitiinfarct dementia \\
\hline Metformin XR & + & N/A & + & ++ & + & + & N/A & + & Once daily & $500-2 \mathrm{~g}$ od & $\mathrm{Cl}, \mathrm{CRF}$, Severe HF \\
\hline Omacor & $\sim /+$ & $?$ & + & $\sim /+$ & $\sim /+$ & $\sim /+$ & $\sim /+$ & + & $\begin{array}{l}\text { Tryglyceride } \\
\text { AF } \\
\text { Inflammation }\end{array}$ & $1 \mathrm{~g}$ od & $\begin{array}{l}\text { Apart from GISSI most studies have been } \\
\text { equivocal. External validity issues in RCT. } \\
\text { Anti-inflammatory for arthritis. Cost. }\end{array}$ \\
\hline Vytorin & + & N/A & + & + & + & + & $\mathrm{N} / \mathrm{A}$ & + & $\begin{array}{l}\text { Ezetemibe } \\
\text { Bypass liver }\end{array}$ & 10/10-10/80od & $\begin{array}{l}\text { Pill size. Half statin dose for equal } \\
\text { efficacy. Simvastatin } 80 \mathrm{mg} \text { suicide, } \\
\text { myopathy }\end{array}$ \\
\hline Fluvastatin XR & + & N/A & + & + & + & $\sim$ & N/A & + & $\begin{array}{l}\text { Novel action XR } \\
\text { reduces myopathy }\end{array}$ & $20-80 \mathrm{od}$ & $\begin{array}{l}\text { Low potency in LDL reduction at high } \\
\text { doses. }\end{array}$ \\
\hline
\end{tabular}

This table highlights established therapeutics and potential newer agents that may have a role as first line in carefully selected cohorts. With interpreting the table:

- The evidence for "Other agents" and comorbidities may not be primarily from CHF studies;

- Data from this table collated by Medline search using "drug name" as highlighted and keyword "CCF or CHF or CF or HF;

- Additional Search Limitations for Race: "race or ethnic groups or ethnicity or continental population groups:

- Evidence supplemented by guidelines in AMH, MIMS, PBS and Ref 22

* Higher doses reduce mortality better than lower doses, no substantive placebo controlled RCT, optimum dose uncertain;

** Strongest evidence in the class;

$\Upsilon$ Drug dosing derived from post MI studies;

$\$$ Treatment not shown to reduce CVM or ACM or shown to be non-inferior to a treatment that does:

$\mathrm{ADI}$ - adverse drug interaction; $\mathrm{C}=$ calcium channel blocker; CRF/I - chronic renal failure/lnsufficiency; $\mathrm{D}=$ diuretic; $\mathrm{DHF}$ - diastolic heart failure; DM - diabetes

mellitus; Dose - od once daily, bd twice daily; IHD - ischemic heart disease; IR - insulin resistance; MRA - mineralocorticoid receptor antagonist; NA: Not Available; N/A: Not applicable; - detrimental; equivocal; + positive; ? Unknown effect.

Table 1: Common CHF Therapeutics and Alternative Options. 
due to their limitations. Carvedilol is likely the superior agent due to traditional $\beta \beta$ properties in addition to vasodilatory, anti-ischemic, antioxidant, antiproliferative, endothelium enhancing, renoprotective, and favorable lipid and glycemic profiles via improved insulin sensitivity $[27,46,47]$. It is the only agent with proven benefit in the dialysis dependant cardiorenal syndrome [16]. One criticism has been exclusion of participants with worsening CHF and adverse events in the run in period (6-9\%), lowering the complication rates in treatment arm [34]. Difficulties for the NT include bd dosing, hypotensive effects, achieving top dose and reduced quality of life data in some studies. Metoprolol XR, bisoprolol have neutral or negative effects on metabolic profiles, renal blood flow and nocturnal melatonin levels [29]. Of interest is Nebivolol, highly selective with vasodilatory properties through NO potentiation. It shares similar extra cardiac benefits of carvedilol and in addition is the most potent (1/10th dose of atenolol) and well tolerated $\beta \beta$ for HT. By decreasing peripheral resistance and increasing stroke volume, this effect also increases cardiac output and exercise capacity compared to traditional $\beta \beta$ that blunts CO. Positive effects are seen in renal function/serum $\mathrm{K}+$, erectile function, COAD and pulmonary pressures with an evolving understanding on sleep and cognitive function $[13,29,47,48]$. There has been some debate over the extent of clinical benefit as NO donor and strength of evidence in severe HF, but is an agent that deserves strong consideration. In HF with vascular disease and metabolic-renal comorbidities, including those at risk, vasodilating $\beta \beta$ 's, which increases blood flow to muscle, kidney and affected organs should be preferred [29,47].

RAAS blockade with ACE-I or ARB where ACE-I is contraindicated is gold standard. The most robust CHF evidence lies with Ramipril/ Enalapril (ACE-I) and Candersartan/Valsartan (ARB). If the playing field was level the benefits are likely a "class effect" with minor variations [49-51]. Difference in glucose metabolism and IR favor ARB $[26,49]$. The lack of combination therapy and blood pressure lowering effects in racial subgroups and bd dosing for full CHF benefits (ramipril/enalapril) are small concerns with these first line agents. Other agents e.g. Lisinopril and Losartan are less competitive options due to availability, familiarity of use, maximal effects being dose related and racial disparities in efficacy. Some personal experience suggests that ACE-I's are not as effective as ARB in indigenous patients as sighted in previous studies [52-54]. Preventive effects are strongest with Ramipril and Telmisartan. In the NT context several agents to consider are Perindopril, which only has evidence in the elderly, as it starts at a very low dose, has combination with diuretic and calcium blocker, is relatively easy to use and has good blood pressure lowering effects. Among the ARB's, Telmisartan has the most robust evidence for blood pressure control including early morning and sustained 24 hour control (relevant for undiagnosed OSA, tropical climate), prevention in high risk groups (similar efficacy to Ramipril), tolerability and efficacy in ethnic subgroups, favorable glucose and lipid metabolism by improved or abolish IR (strongest effects on PPAR- $\gamma$ activation), inflammation (reduces hs-CRP) and in combination with diuretic may not affect serum $\mathrm{K}+$ level. Strong evidence for HF lies in high-risk CRF patients [53-59]. It also has combination with CCB and diuretic and should be given consideration. Aldosterone blockade is vital for class III-IV, perhaps even lower classes. Spironolactone has greater sideeffect profile, adverse drug interactions, effects of glucose metabolism by increasing serum cortisol and HbAlc, may worsen endothelial function, heart rate variability and angiotensin II levels in DM. Eplerenone may be preferred due to specificity and side effect profile. Adverse drug interactions, renin levels in blacks and high serum $\mathrm{K}+$ levels suggest cautious use in some groups $[52,60,61]$.
DM, IR and glycemic control demonstrate a J-curve effect in CHF. Metformin remains the insulin sensitizer of choice. Thiazolidenediones and metformin are relatively $\mathrm{CI}$ in all/severe $\mathrm{CHF}$ respectively. Important factors to consider are good rather than intense glycemic control, with intensive blood pressure, lipid and risk factor control that could reduce RR of CHF by $56 \%$ [6]. Choice of CHF prognostic agents are important considerations as is holistic approach to nutrition, exercise and weight. Diagnosis and treatment of OSA is also critical. Diuretics effect on extracellular $\mathrm{K}+$ and non-selective $\beta \beta$ effect on glycemic control are concerns. Combination of calcium blocker e.g amlodipine or vasodilating $\beta \beta$ or lower strength diuretic with potent RAAS blockade can negate this risk [6,21,29,31,62-69]. Finally, cashing in on post-op weight loss with extended rehab and support are factors to discuss at unit case conferences, and when all options fail bariatric surgery in selected patients $[15,70,71]$.

Intensive lipid control with statins targeting absolute serum values or a percentage decrease, lowest levels for acute coronary syndromes and high absolute cardiovascular risk, are recommended for all CHF except isolated non-ischemic HF. High doses with Atorvastatin leads the evidence in the ischemic setting. Class effects are anti-ischemic, anti-oxidant, anti-arrhythmic and anti-inflammatory. Differences predominate in side effect profiles, drug interactions, potency and level of evidence from RCT. Compliance, at best approaching 50-70\%, 50\% stop at 1 year due to side effects, impacts on optimal benefits [72-76]. Several agents to consider: Fluvastatin XR which is less potent but least likely to exert muscle toxicity and; Ezetrol, a novel agent with lower potency where some consider the jury still out from concerns of long term cancer risk and strength of evidence, can fill this space with its combination as Vytorin which has positive outcomes in high risk CRF cohort [77,78]. From a compliance perspective Vytorin 10/20-10/40 $\mathrm{mg}$ is significantly smaller than Lipitor $40-80 \mathrm{mg}(12.5 \mathrm{~mm}$ vs. $14 / 19$ $\mathrm{mm}$ ) with similar efficacy and less side effects. In discussion with a colleague, he mentioned the humorous term "horse pill' in NHS circles, this is unlikely to be shared by all clients. This combination may also have fewer effects on ubiquinone/CoQ10 levels [6]. Finally myopathy and renal failure risk at high doses strengthens this argument [7981]. Omega III a vital component of all cells and serum lipid profiles, with potent anti-inflammatory effects, has shown robust evidence in small research studies and post MI studies leading to the 'Heart Foundation Fish Oil Program'. Recent studies have been mixed the most encouraging are higher omega III levels associated with lower $\mathrm{CV}$ deaths and increased survival [82-85]. Gray et al. showed that women aged over 65 gained almost twice the muscle strength following exercise with omega III. Nutritional concerns, lack of availability of omega III rich foods may raise questions about the external validity of negative studies for the NT [86]. The proven agent Omacor is expensive and administrators will debate cost benefit. One way forward in this lipid debate is encourage moderate exercise, with combination of low potency statin and a regular intake of oily fish fatty acids.

Other areas to consider are: Duration of dual antiplatelet therapy for high-risk primary prevention and secondary prevention, when events occur on one agent and when drug eluting stents are inserted. Geographical distance and unavailability of primary PCI may guide future thinking on this; Atrial fibrillation-is difficult to treat. Amiodarone is preferred and sotalol may be detrimental in CHF. A combination of $\beta \beta$, RAAS blocker, omega III and cautious use of digoxin (higher levels increases mortality), while understanding ACE-I effect on AF was greatest in CHF and no CHF class $\beta \beta$ is superior for rhythm control. Contentious areas are antiplatelet use with warfarin, measures to maintain atria structure and function, valve intervention 
Citation: lyngkaran P, Thomas M, Sanders P, Hare DL, Majoni W, et al. (2013) Do we need a Wider Therapeutic Paradigm for Heart Failure with Comorbidities? - A Remote Australian Perspective. Health Care Current Reviews 1: 106. doi: 10.4172/2375-4273.1000106

Key Points:

1. Mortality higher in epidemiological studies than trials

2. Mortality still higher than most cancers - likely worse in the NT

3. Etiology and co-morbidities require consideration in prescription

4. Any condition that leads to alteration of LV structure or function can predispose a patient to developing HF.

5. Valvular Heart Disease - LA size/function important in long term health

6. Secondary prevention of HF is well established and includes adequate dosing, compliance and follow-up.

Ways forward

1. Communication with Funding Bodies

a. New Approaches for direct Communication with Funding Bodies (PBS) and Practicing Clinicians in High Risk Area

b. Audits/Proposals for a fixed term e.g. 2 years

c. Medications accepted in the proposal could be used as 1 st line

2. Research

a. Clinical Trial Agreement - avenues for indemnity and drug supply through PBS

b. Observational and Audit based research co-administered by NT Department of Health to ensure accountability, assess cost and outcomes

c. Departmental

i. Support and Encouragement for clinicians to submit proposals under NHMRC area of need and funding priorities

ii. Memorandum of Understanding with potential collaborators to facilitate higher level research and funding opportunities

3. Study Conduct

a. Physiological focus (open label - clinician decide agent)

b. Implementation focus for novel drugs

c. Perfecting population level KPI

Figure 3: Options to Move Forward

in context of atrial size, preventive measures in RHD beyond prophylactic antibiotics and the invasive EP ablation options. The significance of maintaining sinus rhythm should not be understated $[17,87]$. Depression has been previously well covered, is vital but often overlooked and affects outcomes $[19,88]$.

In conclusion complex patients are underrepresented in RCT. The optimal choice of pill burden for client satisfaction, doctor consistency, on outcomes and cost are difficult to decipher. A patient centered approach may however reduce cost and improve outcomes [89]. Figure 3 highlights several options for choice and accountability within the system.

\section{Conclusion}

Pharmacological therapeutics has contributed to significant improvements in the lives of HF patients. There are regions and groups, in the NT, who have not seen the full benefit when a rigid approach to evidence is applied. It is not possible to replicate studies for all conditions and it is incorrect to deny that the evidence represents the wider communities. Thus we do not propose to negate the findings of RCT or question them in great length on each occasion; however external validity is an important consideration. The consumer driven free market system has created multiple agents which do mainly the same things but with other competing benefits. Unless there are vast differences in benefits of one agent over another, physiological principles could guide practice. This will allow using agents with effects beyond their class, improved side effect profiles and as combinations. It appears that physicians interpret evidence heterogeneously as could their view of diseases for e.g. terms such as delay progression, prevent onset, reduce risk can be used interchangeably depending on which is considered the primary illness, the comorbidity or the future risk. To prevent unilateral decisions, new approaches that involve communication with State or Federal Health Funding bodies, advancing a proposal with an audit-based follow up system could be one way forward. Strengthening collaborations and encouraging area of need physicians to explore NHMRC Health Priority Areas funding is important. Ultimately in any system the status quo can never remain as evidence continues to move our field forward. A common sense, accountable system that provides both client and doctor choices would be a positive way forward. Finally, as Krumholz proposed "it is essential that those held accountable have the processes of care being assessed under their locus of control".

\section{References}

1. lyngkaran P, Majoni V, Haste M, Nadarajan K, Battersby M, et al. (2013) Australian Indigenous Chronic Disease Optimization Study (AUSI-CDS) Prospective observational cohort study to determine if an established chronic disease health care model can be used to deliver better heart failure care among Remote Indigenous Australians: Proof of concept. Study Rationale and Protocol. Heart, Lung and Circulation [EPUB].

2. Iyngkaran $P$, Harris $M$, Nadarajan $K$, Ilton $M$, Battersby $M$, et al. 
Citation: Iyngkaran P, Thomas M, Sanders P, Hare DL, Majoni W, et al. (2013) Do we need a Wider Therapeutic Paradigm for Heart Failure with Comorbidities? - A Remote Australian Perspective. Health Care Current Reviews 1: 106. doi: 10.4172/2375-4273.1000106

Implementing Guideline Based Heart Failure Care in the Northern Territory: Challenges and Solutions. Heart Lung \& Circulation 2013 (accepted).

3. Woods JA, Katzenellenbogen JM, Davidson PM, Thompson SC (2012) Heart Failure among Indigenous Australians: a systematic review. BMC Cardiovasc Disord 12: 99

4. Boyd CM, Vollenweider D, Puhan MA (2012) Informing Evidence-Based Decision-Making for Patients with Comorbidity: Availability of Necessary Information in Clinical Trials for Chronic Disease. PLos One 7: e41601.

5. Mutasingwa DR, Ge H, Upshur REG (2011) How applicable are clinical practice guidelines to elderly patients with comorbidities? Can Fam Physician 57: 253-262.

6. Krum H, Gilbert RE (2003) Demographics and concomitant disorders in heart failure. Lancet 362: 147-158.

7. Lang CC, Mancini DM (2007) Non-cardiac comorbidities in chronic heart failure. Heart 93: 665-671.

8. Dahlstrom U (2005) Frequent non-cardiac comorbidities in patients with chronic heart failure. Euro J Heart Failure 7: 309-316.

9. Page RL, Lindenfeld J (2012) Conditions in the Heart Failure Patient. Curr Cardiol Rep 14: 276-284

10. Triposkiadis FK, Skoularigis J (2012) Prevalence and Importance of comorbidities in patients with heart failure. Curr Heart Fail Rep 9: 354-362.

11. Matsuhita K, Blecker S, Pazin-Filho A, Bertoni A, Chang PP, et al. (2010) The Association of Hemoglobin A1c With Incident Heart Failure Among People Without Diabetes: The Atherosclerosis Risk in Communities Study. Diabetes 59: 2020-2026.

12. Gaddam KK, Ventura HO, Lavie CJ (2011) Metabolic Syndrome and Hear Failure-The Risk, Paradox, and Treatment. Curr Hypertens Rep 13: 142-148.

13. Manrique C, Lastra G, Gardner M, Sowers JR (2009) The Renin Angiotensin Aldosterone System in Hypertension: Roles of Insulin Resistance and Oxidative Stress. Med Clin North Am 93: 569-582.

14. Baquet JP, Barone-Rochette G, Tamisier R, Levy P, Pepin JL (2012) Mechanism of cardiac dysfunction in obstructive sleep apnea. Nat Rev Cardio 9: 679-688.

15. Ashrafian H, le Roux CW, Darzi A, Athanasiou T (2008) Effects of Bariatric Surgery on Cardiovascular Function. Circulation 118: 2091-2102.

16. lyngkaran P, Majoni W, Anavekar N, Thomas M, Ronco C (2012) Comorbid Heart Failure and Renal Impairment: Epidemiology and Management. Cardiorenal Med 2: 281-297.

17. Deedwania PC, Lardizabal JA (2010) Atrial Fibrillation in Heart Failure: A Comprehensive Review. Am J Med 123: 198-204.

18. Schwarz ER, Rastogi S, Kapur V, Sulemanjee N, Rodriguez JJ (2006) Erectile Dysfunction in Heart Failure Patients. J Am Coll Cardiol 48: 1111-1119.

19. Woltz PC, Chapa DW, Friedman E, Son H, Akintade B, et al. (2013) Effects of interventions on depression in heart failure: A systematic review. Heart \& Lung 41: $469-483$

20. Walsh CR, Larson MG, Evans JC, Djousse L, Ellison RC, et al. (2002) Alcoho consumption and risk for congestive heart failure in the Framingham Heart Study. Ann Intern Med 136: 181-191.

21. Ferrannini E, Cushman WC (2012) Diabetes and hypertension: the bad companions. Lancet 380: 601-610.

22. McMurray JJV, Adamopoulos S, Anker SD, Auricchio A, Bohm M, et al. (2012) ESC Guidelines for the diagnosis and treatment of acute and chronic heart failure 2012. Eur Heart J 33: 1787-1847.

23. Braga MFB, Leiter LA (2009) Role of Renin-Angiotensin System Blockade in Patients with Diabetes Mellitus. Am J Cardiol 104: 835-839.

24. Oikonomou E, Tousoulis D, Siasos G, Zaromitidou M, Papavassiliou AG et al. (2011) The Role of Inflammation in Heart Failure: New Therapeutic Approaches. Hellenic J Cardiol 52: 30-40.

25. Luiking YC, Engelen MPKJ, Deutz NEP (2010) Regulation of Nitric Oxide Production in Health and Disease. Curr Opin Clin Nutr Metab Care 13: 97-104.

26. McGuire DK, Winterfiled JR, Rytlewski JA, Ferrannini E (2008) Blocking the rennin-angiotensin-aldosterone system to prevent diabetes mellitus. Diabetes Vasc Dis Res 5: 59-66.
27. lyngkaran P, Anavekar N, Majoni W, Thomas MC (2013) The role and management of sympathetic overactivity in cardiovascular and renal complications of diabetes. Diabetes Metab 39: 290-298.

28. Ansley DM, Wang B (2013) Oxidative stress and myocardial injury in the diabetic heart. J Pathol 229: 232-241.

29. Orasanu G, Plutzky J (2009) The Pathologic Continuum of Diabetic Vascular Disease. J Am Coll Cardiol 53: 35-42.

30. Marti CN, Gheorghiade M, Kaloreropoulos AP, Georgiopoulou VV, Quyyum AA, et al. (2012) Endothelial Dysfunction and Arterial Stiffness, and Heart Failure. J Am Coll Cardiol 60: 1455-1469.

31. Nolan CJ, Damm P, Prentki M (2011) Type 2 diabetes across generations: from pathophysiology to prevention and management Lancet 378: 169-181.

32. Hegab Z, Gibbons S, Neyses L, Mamas MA (2012) Role of advanced glycation end products in cardiovascular disease. World J Cardiol 4: 90-102.

33. McAlister FA, Laupacis A, Wells GA, Sackett DL (1999) Users' Guides to the Medical Literature: XIX. Applying clinical trial results B. Guidelines for determining whether a drug is exerting (more than) a class effect. JAMA 282 1371-1377.

34. Rothwell PM (2012) Factors That Can Affect the External Validity of Randomised Controlled Trials. PLOS Clin Trials 1: e9.

35. Ho PM, Peterson PN, Masoudi FA (2008) Evaluating the Evidence: Is there a Rigid Hierachy? Circulation 118: 1675-1684.

36. Interpreting and Using Clinical Trials (1998) An Evidence-based approach to Critical Care Medicine, W. B. Saunders Company, Philadelphia.

37. Furberg CD, Pitt B (2001) Are all angiotensin-converting enzyme inhibitors interchangeable? J Am Coll Cardiol 37: 1456-1460.

38. ChanAW, Hro bjartsson A, Haahr MT, Gøtzsche PC, Altman DG (2004) Empirical Evidence for Selecting Reporting of Outcomes in Randomized Trials: Comparison of Protocols to Published Articles. JAMA 291: 2457-2465.

39. Boutron I, Dutton S, Ravaud P, Altman DG (2010) Reporting and Interpretation of Randomized Controlled Trials with Statistically Nonsignifcant Results for Primary Outcomes. JAMA 303: 2058-2064.

40. Jones R, Jones RO, McCowan C, Montgomery AA, Fahey T (2009) The external validity of published randomized controlled trials in primary care. BMC Family Practice 10: 5

41. Yank V, Rennie D, Bero LA (2007) Financial ties and concordance between results and conclusions in meta-analysis: retrospective cohort study. BMJ 335 : 1202-1205.

42. Song F, Hooper L, Loke YK (2013) Publication bias:what is it? How do we measure it? How do we avoid it? Open Access Journal of Clinical Trials 5 : $71-81$.

43. Fitzgerald AA, Powers JD, Ho PM, Maddox TM, Peterson PN, et al. (2011) Impact of medication nonadherence on hospitalizations and mortality in heart failure. J Card Fail 17: 664-669.

44. Chatterjee S, Biondi-Zoccai G, Abbate A, D'Ascenzo F, Castagno D, et al (2013) Benefits of $\beta$ blockers in patients with heart failure and reduced ejection fraction: network meta-analysis. BMJ 346: 55.

45. McAlister FA, Wiebe N, Ezekowitz JA, Leung AA, Armstrong PW (2009) Metaanalysis: beta-blocker dose, heart rate reduction, and death in patients with heart failure. Ann Intern Med 150: 784-794.

46. Feldman D, Elton TS, Menachemi DM, Wexler RK (2010) Heart rate contro with adrenergic blockade: Clinical outcomes in cardiovascular medicine. Vasc Health Risk Manag 6: 387-397

47. Baliga RR, Young JB (2012) $\beta$-Blockers in Heart Failure: Breaking Tradition to Avoid Diabetes. Heart Fail Clin 8: 13-16.

48. Toblli JE, DiGennaro F, Giani JF, Dominici FP (2012) Nebivolol: impact on cardiac and endothelial function and clinical utility. Vasc Health Risk Manag 8: 151-160.

49. Volpe M (2012) Should all patients at high cardiovascular risk receive reninangiotensin system blockers? QJM 105: 11-27.

50. Hennessy S, Kimmel SE (2004) Is Improved Survival a Class Effect of Angiotensin-Converting Enzyme Inhibitors? Ann Intern Med 141: 157-158. 
Citation: Iyngkaran P, Thomas M, Sanders P, Hare DL, Majoni W, et al. (2013) Do we need a Wider Therapeutic Paradigm for Heart Failure with Comorbidities? - A Remote Australian Perspective. Health Care Current Reviews 1: 106. doi: 10.4172/2375-4273.1000106

Page 9 of 9

51. Pilote L, Abrahamowicz M, Rodrigues E, Eisenberg MJ, Rahme E (2004) Mortality rates in elderly patients who take different angiotensin-converting enzyme inhibitors after acute myocardial infarction: a class effect? Ann Intern Med 141: 102-112

52. Havranek EP (2008) From Black and White to Shades of Gray: Race and Renin-Angiotensin System Blockade. J Am Coll Cardiol 51: 1872-1873.

53. McGill JB, Reilly PA (2001) Combination treatment with telmisartan and hydrochlorothiazide in black patients with mild to moderate hypertension. Clin Cardiol 24: $66-72$.

54. Ben-Yehuda O (2003) Hypertension, Angiotensin II, Aldosterone, and Race. J Am Coll Cardiol 41: 1156-1158.

55. Regional Drug and Therapeutics Centre (2011) Which Angiotensin Receptor Blocker? NHS DRUG UPDATE.

56. Dans AL, Teo K, Gao P, Chen JH, Hyung KJ, et al. (2010) In a Subgroup of High-Risk Asians, Telmisartan Was Non- Inferior to Ramipril and Better Tolerated in the Prevention of Cardiovascular Events. PLoS ONE 5: e13694.

57. Morimoto S, Takahashi N, Morita T, Someya K, Toyoda N, et al. (2010) Critical appraisal and pooled analysis of telmisartan alone or in combination with hydrochlorothiazide for achieving blood pressure goals. Integr Blood Press Control 3: 73-79.

58. Asmar R (2012) Telmisartan in High Cardiovascular Risk Patients. European Cardiology 8: 10-16.

59. Antoniou T, Camacho X, Yao Z, Gomes T, Juurlink DN, et al. (2013) Comparative effectiveness of angiotensin-receptor blockers for preventing macrovascular disease in patients with diabetes: a population-based cohort study. CMAJ 185: 1035-1041.

60. Zannad F, Stough WG, Rossignol P, Bauersachs J, McMurray JV, et al. (2012) Mineralocorticoid receptor antagonists for heart failure with reduced ejection fraction: integrating evidence into clinical practice. Eur Heart J 33: 2782-2795.

61. Ghali JK, Tam SW, Sabolinski ML, Taylor AL, Lindenfeld J, et al. (2008) Exploring the potential synergistic action of spironolactone on nitric oxideenhancing therapy: insights from the African-American Heart Failure Trial. J Card Fail 14: 718-723.

62. Voulgari C, Papadogiannis D, Tentolouris N (2010) Diabetic cardiomyopathy: from the pathophysiology of the cardiac myocytes to current diagnosis and management strategies. Vasc Health Risk Manag 6: 883-903.

63. Eshagian S, Horwich TB, Fonarow GC (2006) An unexpected inverse relationship between $\mathrm{HbA} 1 \mathrm{c}$ levels and mortality in patients with diabetes and advanced systolic heart failure. Am Heart J 151: 91.

64. Boussageon R, Bejan-Angoulvant T, Saadatian-Elahi M, Lafont S, Bergeonneau C, et al. (2011) Effect of intensive glucose lowering treatment on all cause mortality, cardiovascular death, and microvascular events in type 2 diabetes: meta-analysis of randomised controlled trials. BMJ 343: 4169

65. Ascione R, Rogers CA, Rajakaruna C, Angelini GD (2008) Inadequate Blood Glucose Control Is Associated With In-Hospital Mortality and Morbidity in Diabetic and Nondiabetic Patients Undergoing Cardiac Surgery. Circulation 118: 113-123.

66. Van Melle JP, Bot M, De Jonge P, De Boer RA, Van Veldhuisen DJ, et al (2010) Diabetes, Glycemic Control, and New- Onset Heart Failure in Patients With Stable Coronary Artery Disease. Diabetes Care 33: 2084-2089.

67. Opie LH, Yellon DM, Gersh BJ (2011) Controversies in the cardiovascular management of type 2 diabetes. Heart 97: 6-14.

68. Aguilar D, Bozkurt B, Ramasubbu K, Deswal A (2009) Relationship of Hemoglobin A1C and Mortality in Heart Failure Patients With Diabetes. J Am Coll Cardiol 54: 422-428.

69. Goodarzi MO, Psaty BM (2008) Glucose Lowering to Control Macrovascula Disease in Type 2 Diabetes Treating the Wrong Surrogate End Point? JAMA 300: 2051-2503

70. Kaul A, Sharma J (2011) Impact of Bariatric Surgery on Comorbidities. Surg Clin N Am 91: 1295-1312.

71. Schauer PR, Kashyap SR, Wolski K, Brethauer SA, Kirwan JP, et al. (2012) Bariatric surgery versus intensive medical therapy in obese patients with diabetes. N Engl J Med 366: 1567-1576.

72. Maningat P, Gordan BR, Breslow JL (2013) How do we improve patient compliance and adherence to long-term statin therapy? Curr Atheroscler Rep 15: 291

73. Zhang H, Plutzky J, Skentzos S, Morrison F, Mar P, et al. (2013) Discontinuation of Statins in Routine Care Settings: A Cohort Study. Ann Intern Med 158: 526-534

74. Armitage J (2007) The safety of statins in clinical practice Lancet 370: 1781-1790.

75. Gotto AM, Moon JE (2012) Recent Clinical Studies of the Effects of LipidModifying Therapies. Am J Cardiol 110: 15-26.

76. Nicholls SJ, Brandup-Wognsen G, Palmer M, Barter PJ (2010) Metaanalysis of Comparative Efficacy of Increasing Dose of Atorvastatin Versus Rosuvastatin Versus Simvastatin on Lowering Levels of Atherogenic Lipids (from VOYAGER). Am J Cardiol 105: 69-76.

77. Kashani A, Sallam T, Bhemreddy S, Mann DI, Wang Y, et al. (2008) Review of Side-Effect Profile of Combination Ezetimibe and Statin Therapy in Randomized Clinical Trials. Am J Cardiol 101: 1606-1613.

78. Baigent C, Landray MJ, Reith C, Emberson J, Wheeler DC, et al. (2011) The effects of lowering LDL cholesterol with simvastatin plus ezetimibe in patients with chronic kidney disease (Study of Heart and Renal Protection): a randomised placebo-controlled trial. Lancet 377: 2181-2192.

79. Dormuth CR, Hemmelgarn BR, Michael Paterson J, James MT, Teare GF, et al. (2013) Use of high potency statins and rates of admission for acute kidney injury: multicenter, retrospective observational analysis of administrative databases. BMJ 346: 880 .

80. Gabb GM, Vitry A, Limaye V, Alhami G (2013) Serious statin-associated myotoxicity and rhabdomyolysis in Aboriginal and Torres Strait Islanders: a case series. Intern Med J 43: 987-992.

81. Liao JK (2007) Safety and Efficacy of Statins in Asians. Am J Cardiol 99: 410-414

82. http://www.heartfoundation.org.au/SiteCollectionDocuments/Fish-positionstatement.pdf

83. Rizos EC, Ntzani EE, Bika E, Kostapanos MS, Elisaf MS (2012) Association Between Omega-3 Fatty Acid Supplementation and Risk of Major Cardiovascular Disease Events: A Systematic Review and Meta-analysis. JAMA 308: 1024-1033.

84. ORIGIN Trial Investigators, Bosch J, Gerstein HC, Dagenais GR, Díaz R (2012) n-3 Fatty Acids and Cardiovascular Outcomes in Patients with Dysglycemia. N Engl J Med 367: 309-318.

85. Mozaffarian D, Lemaitre RN, King IB, Song Z, Huang H, et al. (2013) Plasma Phospholipid Long-Chain omega-3 Fatty Acids and Total and Cause-Specific Mortality in Older Adults: A Cohort Study. Ann Intern Med 158: 515-525.

86. Brimblecombe JK, Ferguson MM, Liberato SC, O'Dea K (2013) Characteristics of the community-level diet of Aboriginal people in remote northern Australia MJA 198: 380-384.

87. Li-Fern H, Sanders P, Garrigue S, Hocini M, Sacher F, et al. (2004) Catheter Ablation for Atrial Fibrillation in Congestive Heart Failure. N Engl J Med 351 2373-2383.

88. Silver MA (2010) Depression and heart failure: An overview of what we know and don't know. Clev Clin J of Med 77: 7-11

89. Weiner SJ, Schwartz A, Sharma G, Binns-Calvey A, Ashley N, et al. (2013) Patient-Centered Decision Making and Health Care Outcomes: An Observational Study. Ann Intern Med 158: 573-579. 